Supporting Information

\title{
Modeling on a three-way catalyst used in series hybrid electric vehicles focusing on its catalytic behavior at cold start
}

Toshinori Okajima* a,b Suchitra Sivakumar a, Hajime Shingyouchi a, Kyohei Yamaguchi a , Jin Kusaka a , Makoto Nagata ${ }^{b}$.

(a Department of Modern Mechanical Engineering, Graduate School of Creative Science and Engineering, Waseda University, 3-4-1 Okubo, Shinjuku-ku, Tokyo 169-8555, Japan).

(b N.E. Chemcat Corporation, 678 Ipponmatsu, Numazu, Shizuoka 410-0314, Japan).

Corresponding author

Toshinori Okajima

E-mail: *toshinori.okajima@ne-chemcat.co.jp 


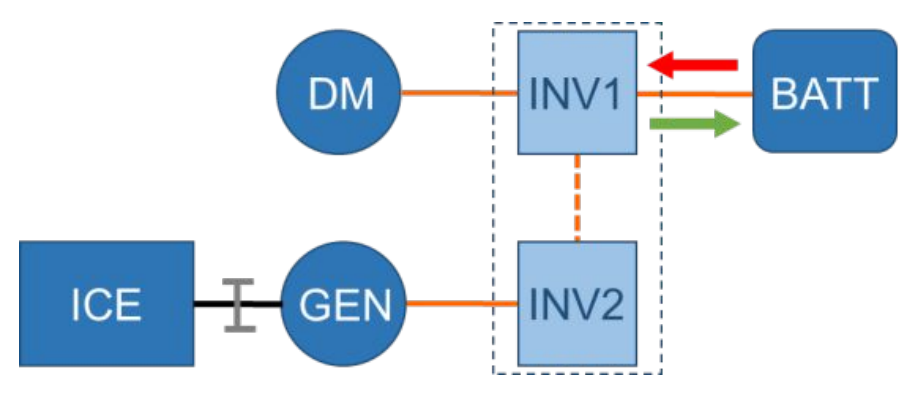

Fig. S1 Powertrain configuration of the tested series hybrid electric vehicle (SHEV), comprising an internal combustion engine (ICE), a generator (GEN), drive motor (DM), two inverters (INV1, INV2), and a battery (BATT) [S1].

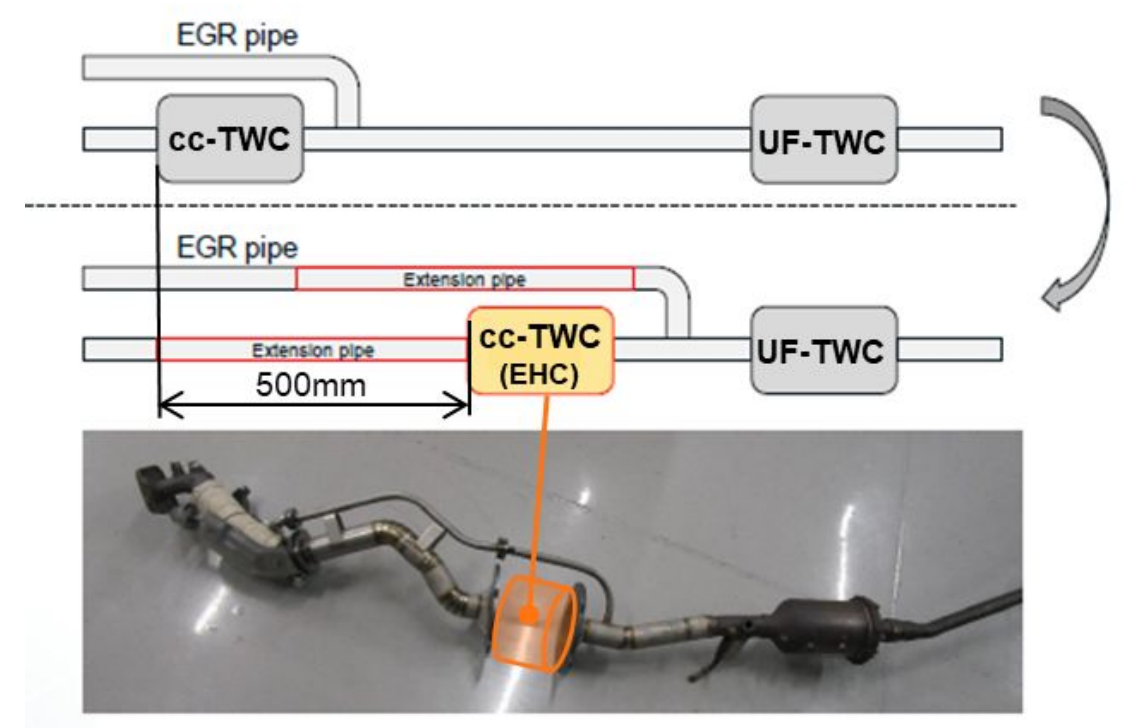

Fig. S2 Layout of the aftertreatment system of the tested SHEV [S1]. 

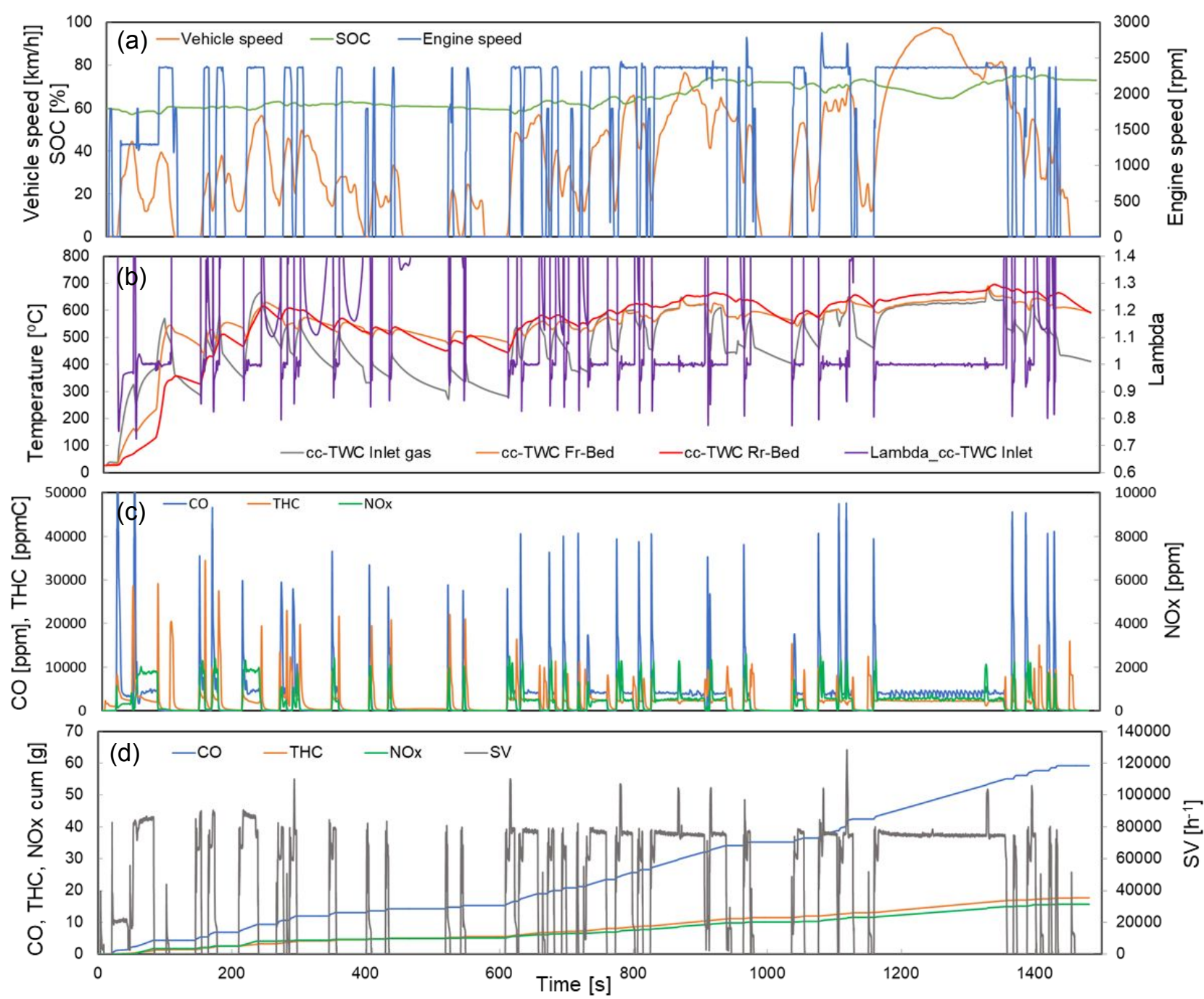

Fig. S3 Vehicle test results in worldwide harmonized light vehicles test cycle (WLTC) mode [S1].

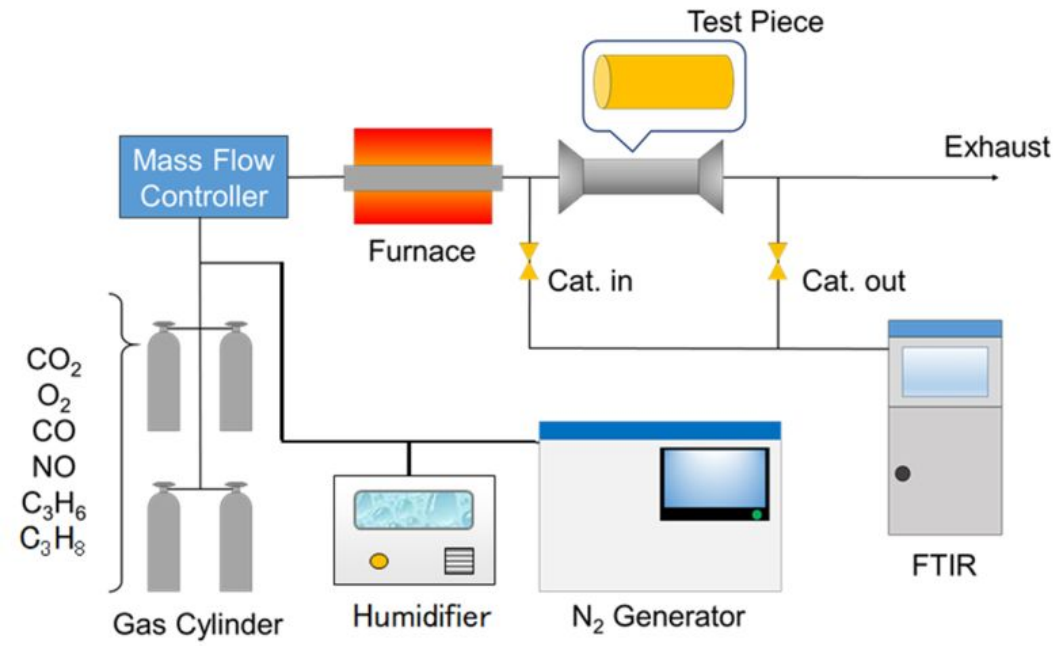

Fig. S4 Schematic of the model gas testing system [S1]. 


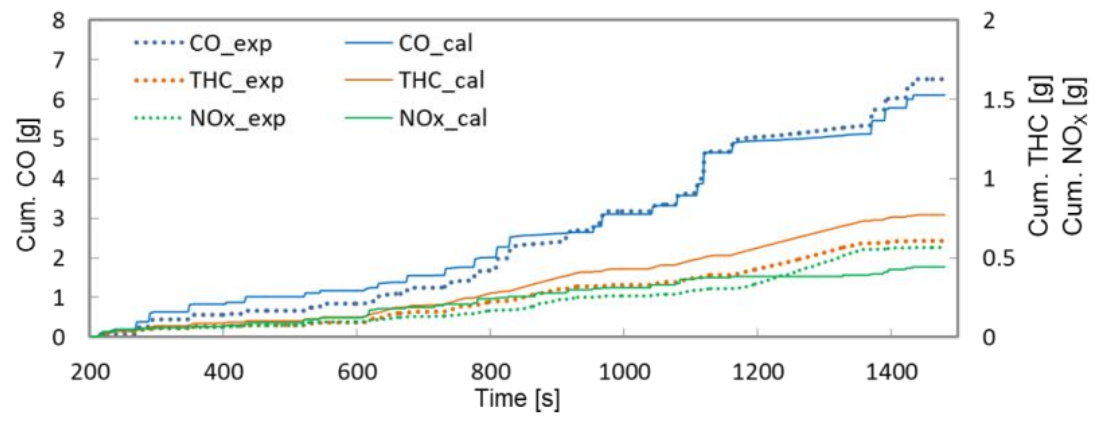

Fig. S5 Comparisons of the experimental and simulated results of the cumulative emission amounts at the cc-TWC outlet in WLTC mode from $200 \mathrm{~s}$ to the end [S1].

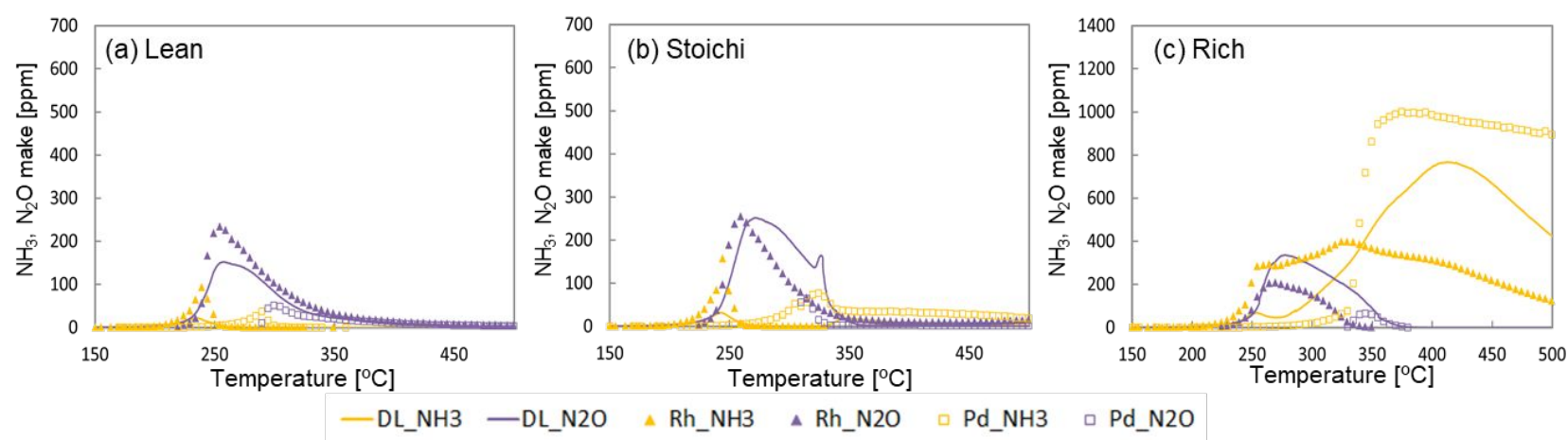

Fig. $\mathrm{S} 6 \mathrm{~N}_{2} \mathrm{O}$ and $\mathrm{NH}_{3}$ generation during light-off test after pre-conditioning with rich gas under each measurement gas condition: (a) lean, (b) stoichiometric, and (c) rich.

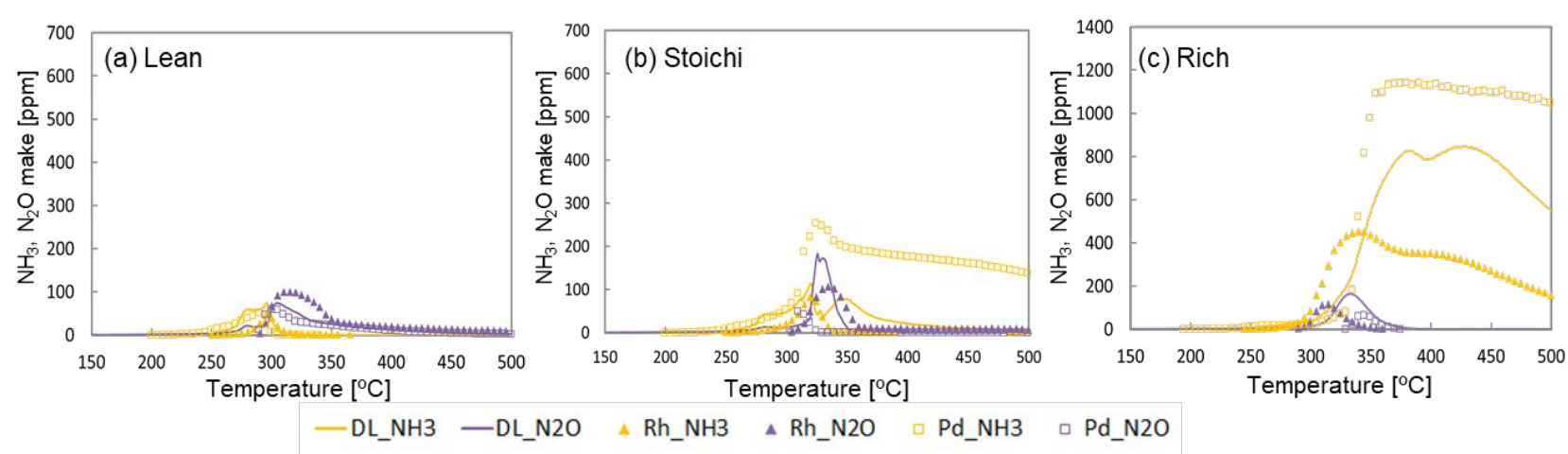

Fig. $\mathrm{S} 7 \mathrm{~N}_{2} \mathrm{O}$ and $\mathrm{NH}_{3}$ generation during light-off test after pre-conditioning with lean gas under each measurement gas condition: (a) lean, (b) stoichiometric, and (c) rich. 

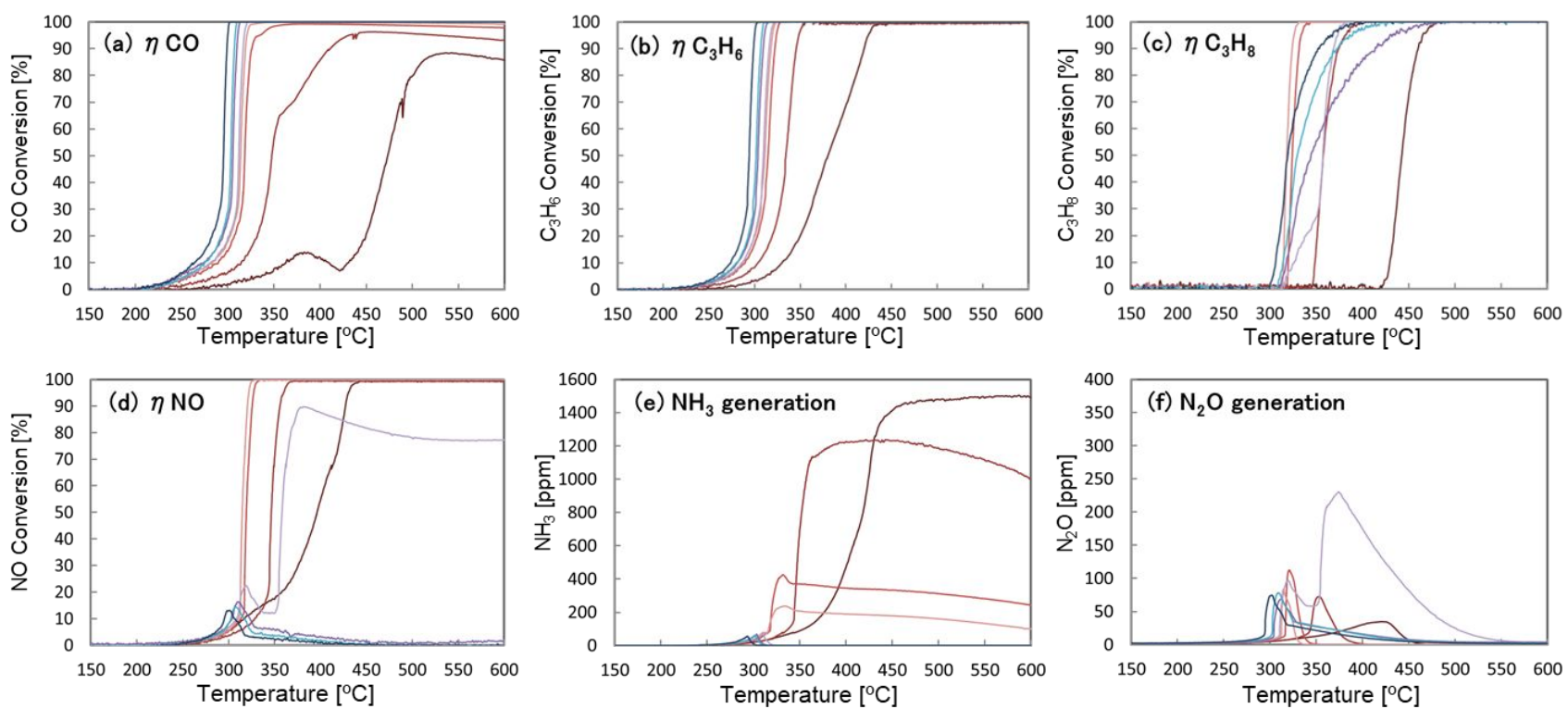

$$
\begin{array}{rrrr}
-\mathrm{Rh} \_\lambda 0.88 & -\mathrm{Rh} \_\lambda 0.94 & -\mathrm{Rh} \lambda 0.98 & -\mathrm{Rh} \lambda 0.99 \\
-\mathrm{Rh} \_\lambda 1.00 & -\mathrm{Rh} \_\lambda 1.02 & -\mathrm{Rh} \lambda 1.03 & -\mathrm{Rh} \lambda 1.05
\end{array}
$$

Fig. S8 Light-off experiment results of Pd single-layer catalyst (Pd-SL) for each $\lambda$ condition: (a) CO conversion, (b) $\mathrm{C}_{3} \mathrm{H}_{6}$ conversion, (c) $\mathrm{NO}_{x}$ conversion, (d) $\mathrm{C}_{3} \mathrm{H}_{8}$ conversion, (e) $\mathrm{NH}_{3}$ generation, and (f) $\mathrm{N}_{2} \mathrm{O}$ generation.
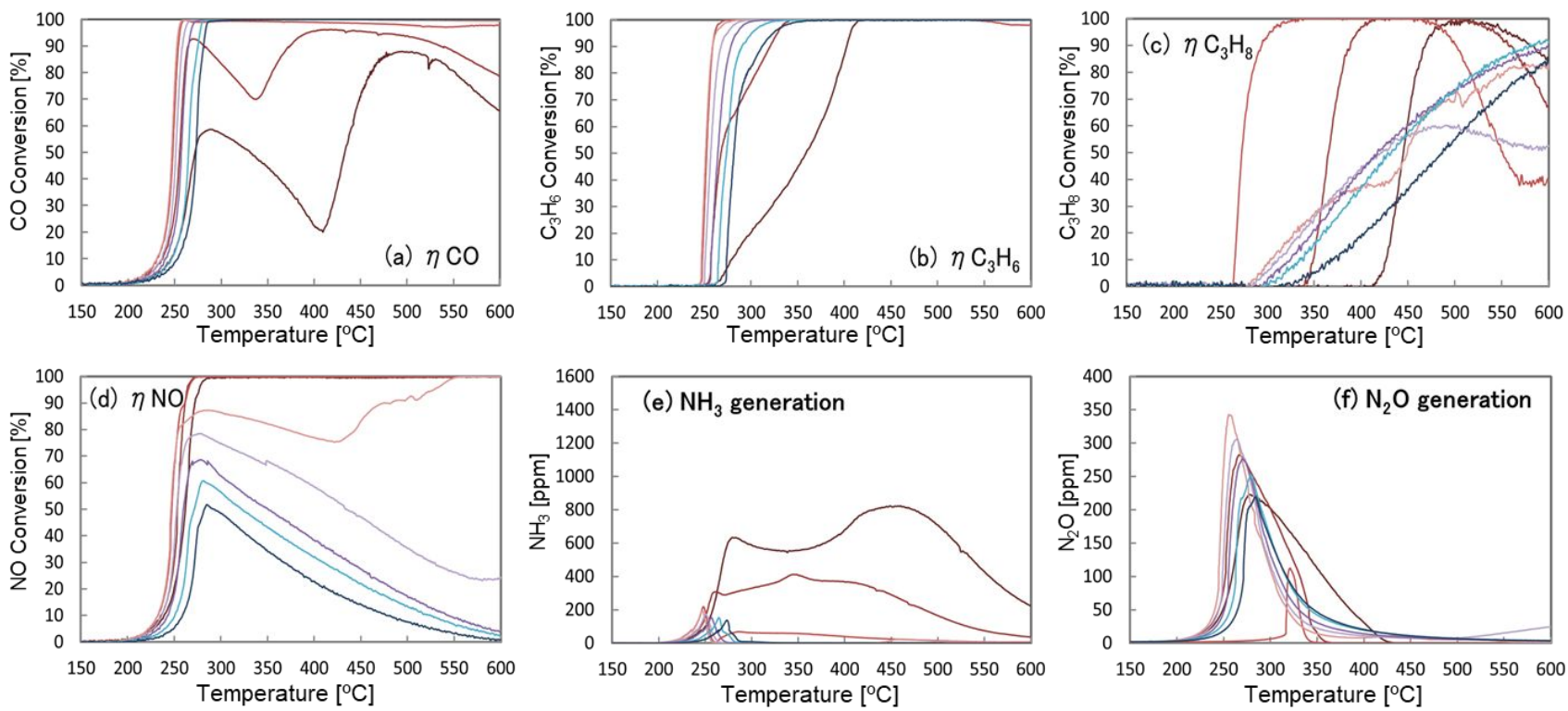

$$
\begin{array}{rrrr}
-\mathrm{Rh} \_\lambda 0.88 & -\mathrm{Rh} \lambda 0.94 & -\mathrm{Rh} \lambda 0.98 & -\mathrm{Rh} \_\lambda 0.99 \\
-\mathrm{Rh} \_\lambda 1.00 & -\mathrm{Rh} \lambda 1.02 & -\mathrm{Rh} \lambda 1.03 & -\mathrm{Rh} \_\lambda 1.05
\end{array}
$$

Fig. S9 Light-off experiment results of Rh single layer catalyst (Rh-SL) for each $\lambda$ condition: (a) CO conversion, (b) $\mathrm{C}_{3} \mathrm{H}_{6}$ conversion, (c) $\mathrm{NO}_{x}$ conversion, (d) $\mathrm{C}_{3} \mathrm{H}_{8}$ conversion, (e) $\mathrm{NH}_{3}$ generation, and (f) $\mathrm{N}_{2} \mathrm{O}$ generation. 

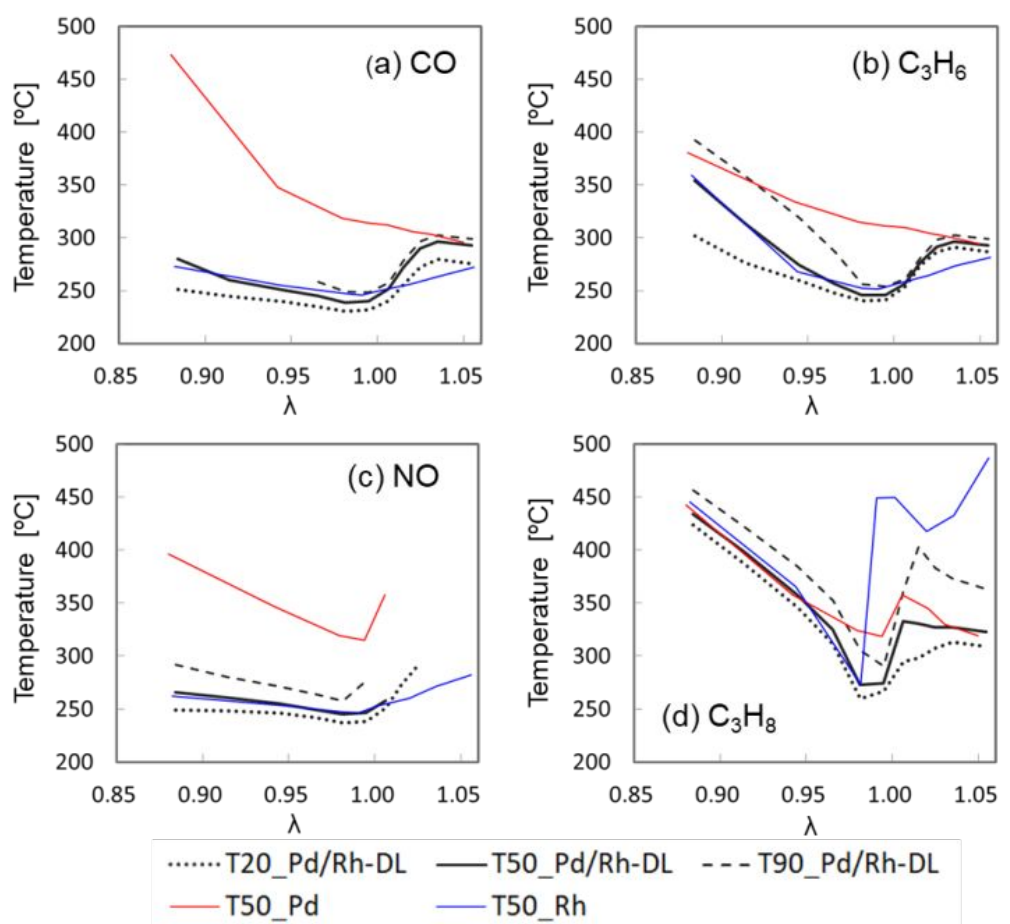

Fig. S10 Comparisons of light-off performances for T20, T50, and T90 among Pd-SL, Rh-SL, and Pd/Rh double-layer catalyst (Pd/Rh-DL) for the conversion rates: (a) $\mathrm{CO}$, (b) $\mathrm{C}_{3} \mathrm{H}_{6}$, (c) NO, and (d) $\mathrm{C}_{3} \mathrm{H}_{8}$.
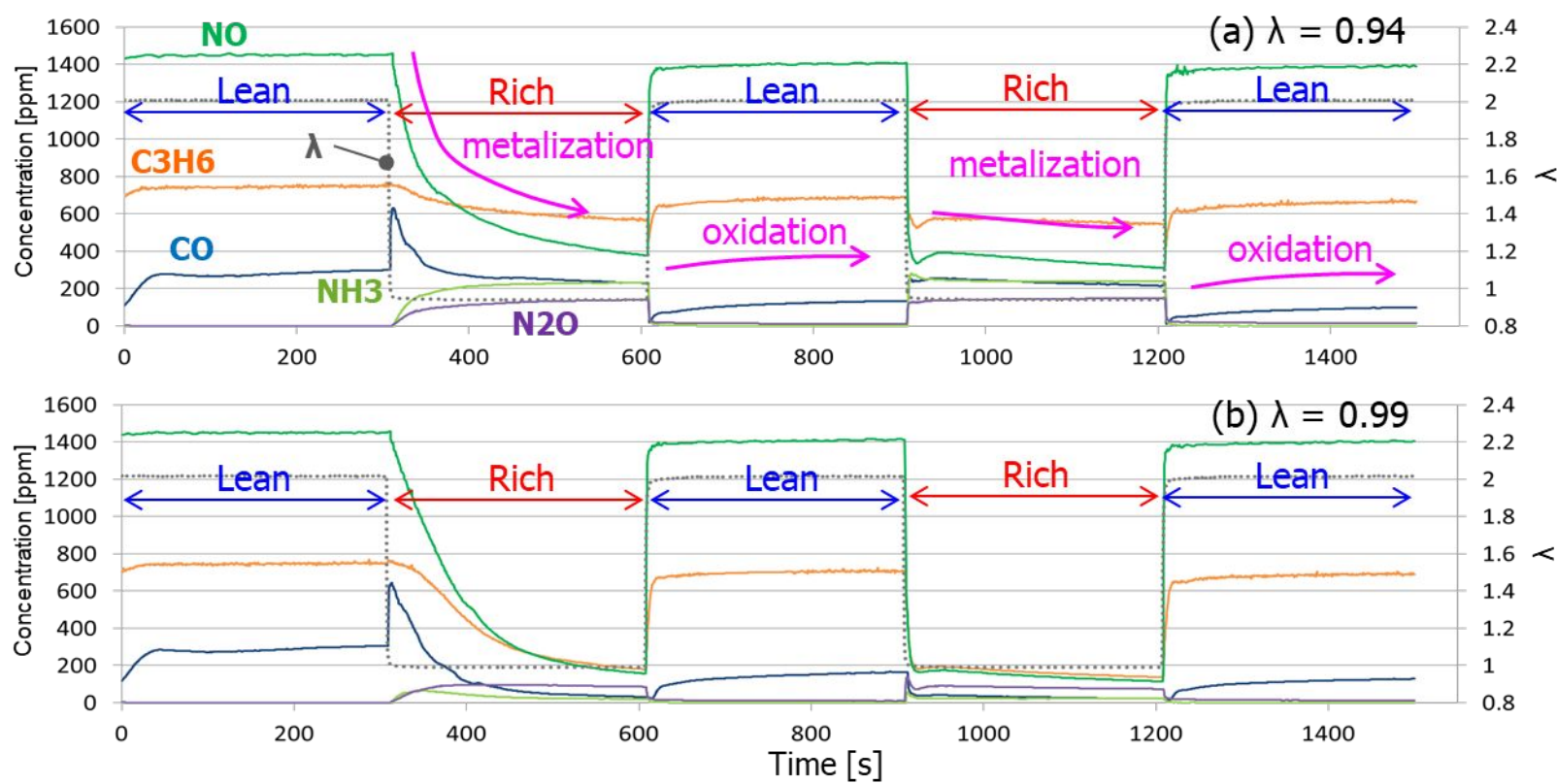

Fig. S11 Lean and rich iteration test results at $300^{\circ} \mathrm{C}$ : (a) $\lambda$ at rich $=0.94$ and (b) $\lambda$ at rich $=0.99$. 
(a) $\lambda=0.88$
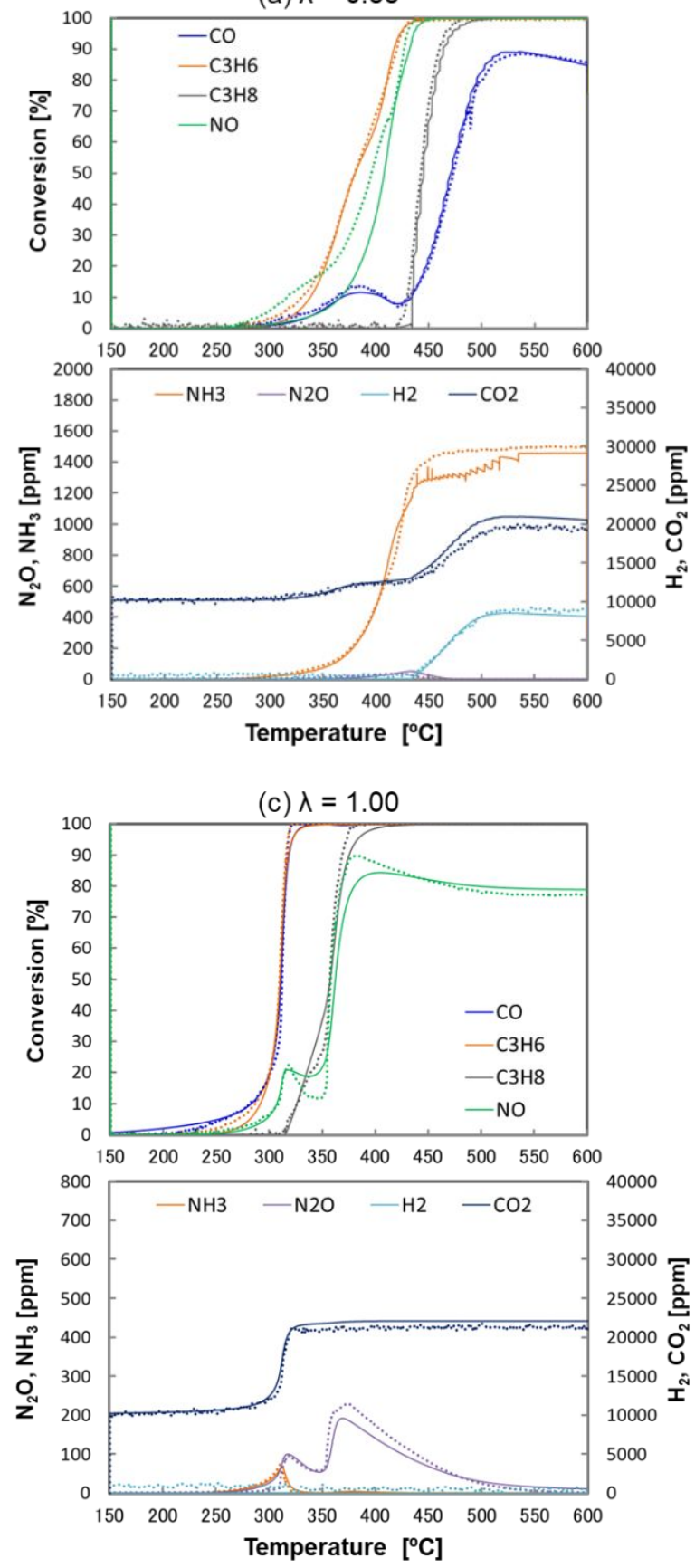

experiment (dashed line) (b) $\lambda=0.98$
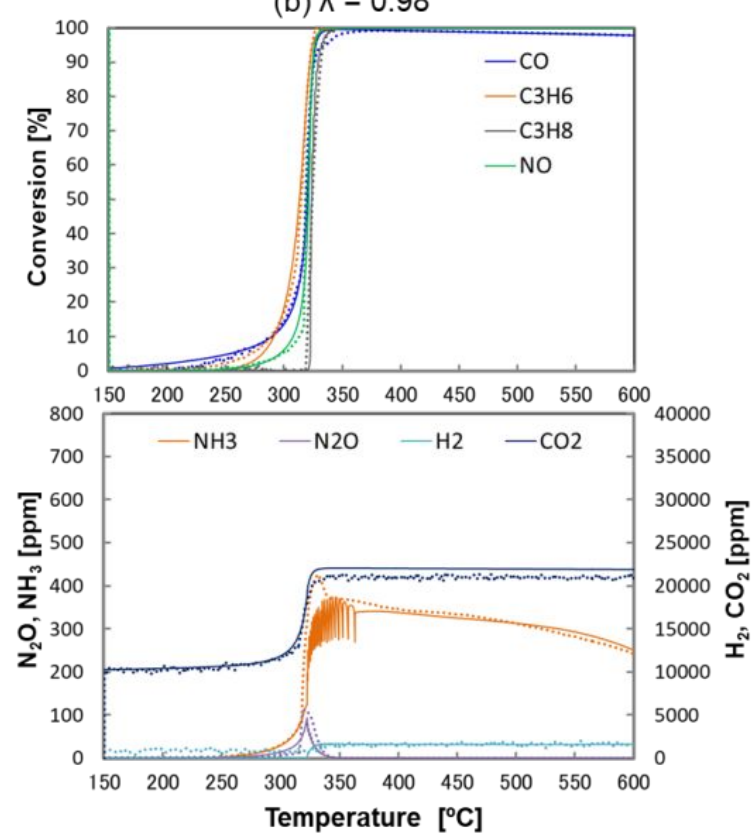

(d) $\lambda=1.03$
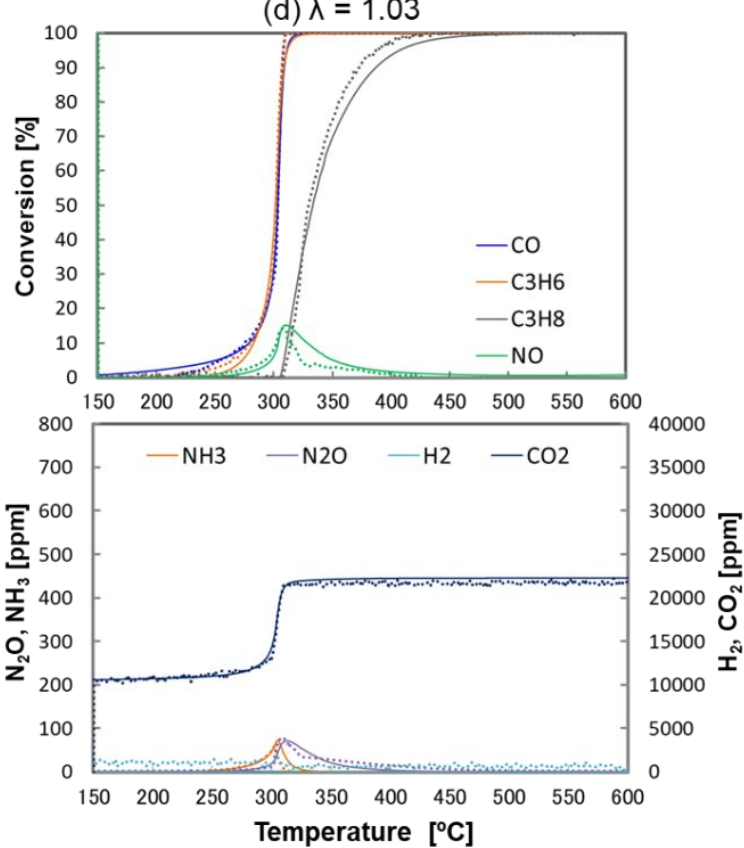

calculation (solid line)

Fig. S12 Light-off profiles of Pd-SL and purification conversion rates for legislated species (top charts) and byproduct concentrations (bottom charts) at $\lambda=$ (a) 0.91 , (b) 0.98 , (c) 1.00 , and (d) 1.03 . 
(a) $\lambda=0.88$

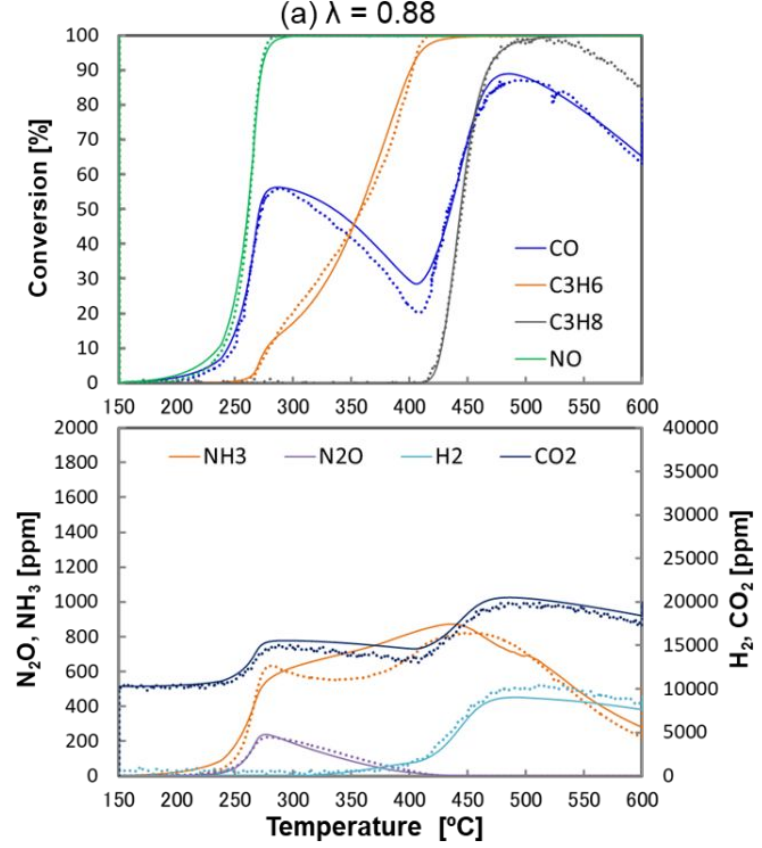

(c) $\lambda=1.00$
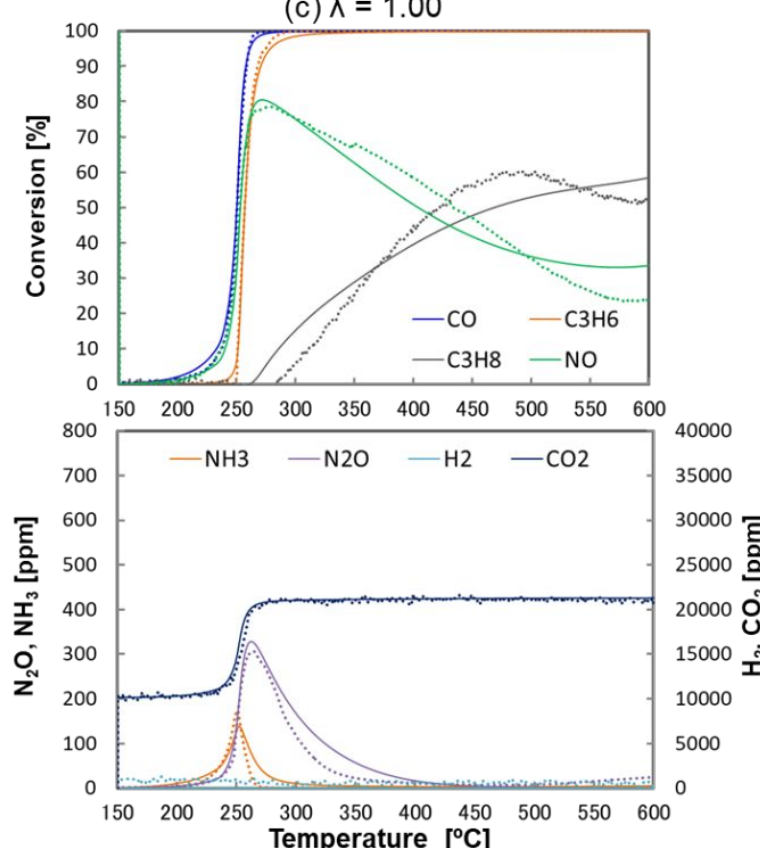

experiment (dashed line)

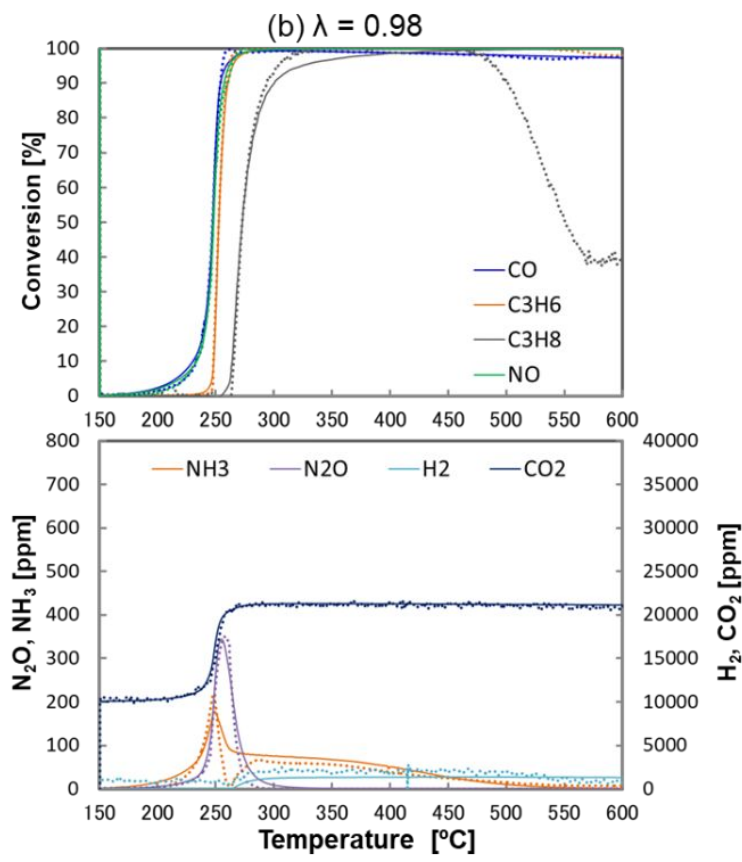

(d) $\lambda=1.03$
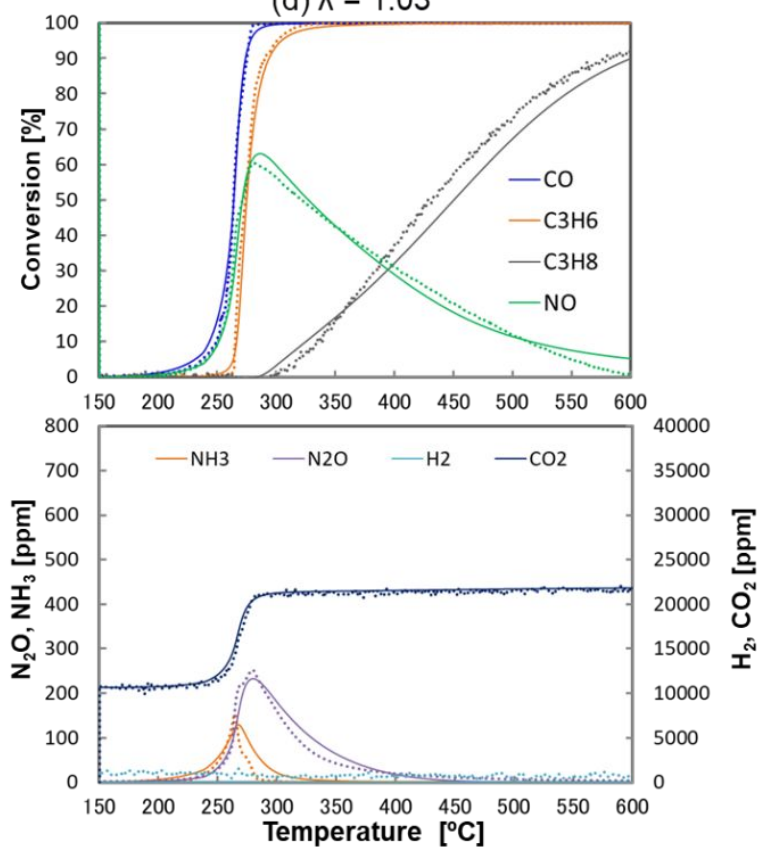

calculation (solid line)

Fig. S13 Light-off profiles of Rh-SL and purification conversion rates for legislated species (top charts) and byproduct concentrations (bottom charts) at $\lambda=$ (a) 0.91 , (b) 0.98 , (c) 1.00 , and (d) 1.03 . 
(a) No. $1 ; \mathrm{CO}+\mathrm{O}_{2}$

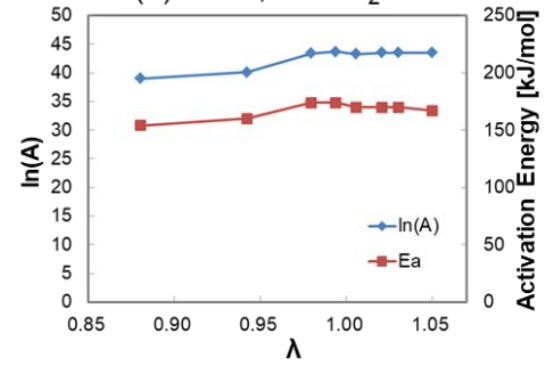

(d) No. 17; WGS \& No. 18; RWGS

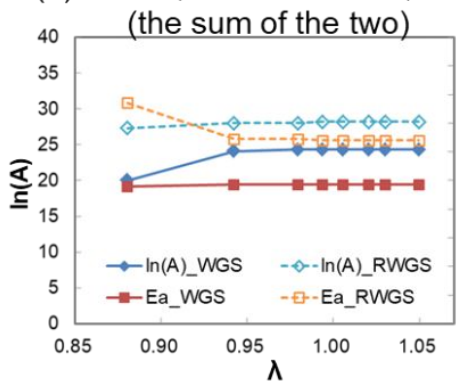

(b) No. $2 ; \mathrm{C}_{3} \mathrm{H}_{6}+4.5 \mathrm{O}_{2}$

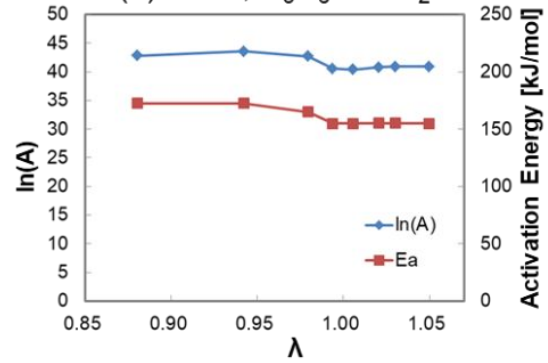

(c) No. $6 ; 5 \mathrm{CO}+2 \mathrm{NO}+3 \mathrm{H}_{2} \mathrm{O}$

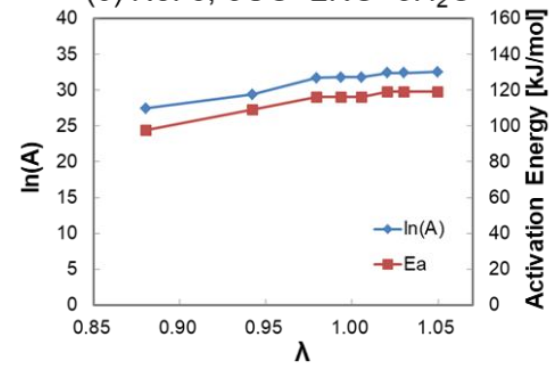

Fig. S14 Transitions in the kinetic parameters of Pd-SL for six typical reactions with varying $\lambda$.

(a) No. $1 ; \mathrm{CO}+\mathrm{O}_{2}$

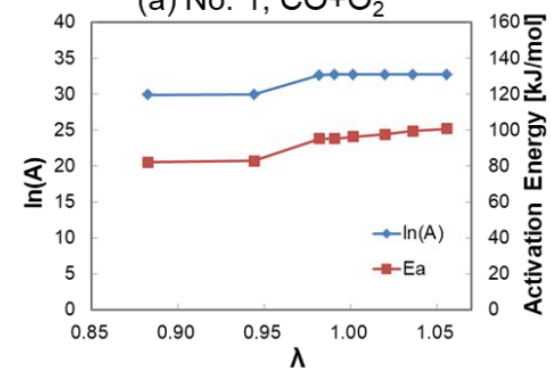

(e) No. $13 ; 2 \mathrm{NO}+5 \mathrm{H}_{2}$

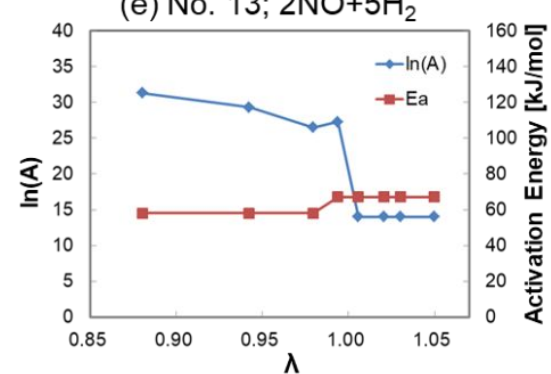

(f) No. $16 ; 2 \mathrm{NH}_{3}+8 \mathrm{NO}$

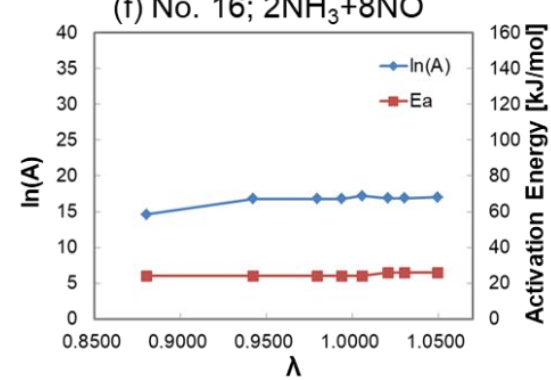

(d) No. 17; WGS \& No. 18; RWGS

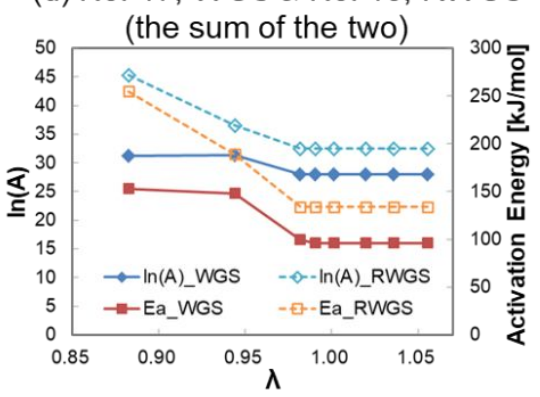

(b) No. $2 ; \mathrm{C}_{3} \mathrm{H}_{6}+4.5 \mathrm{O}_{2}$

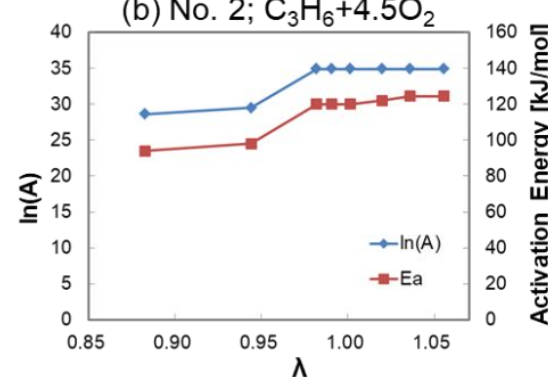

(c) No. 6; $5 \mathrm{CO}+2 \mathrm{NO}+3 \mathrm{H}_{2} \mathrm{O}$

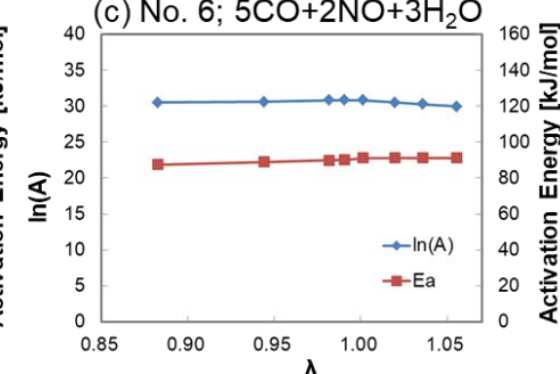

Fig. S15 Transitions in the kinetic parameters of Rh-SL for six typical reactions with varying $\lambda$. 

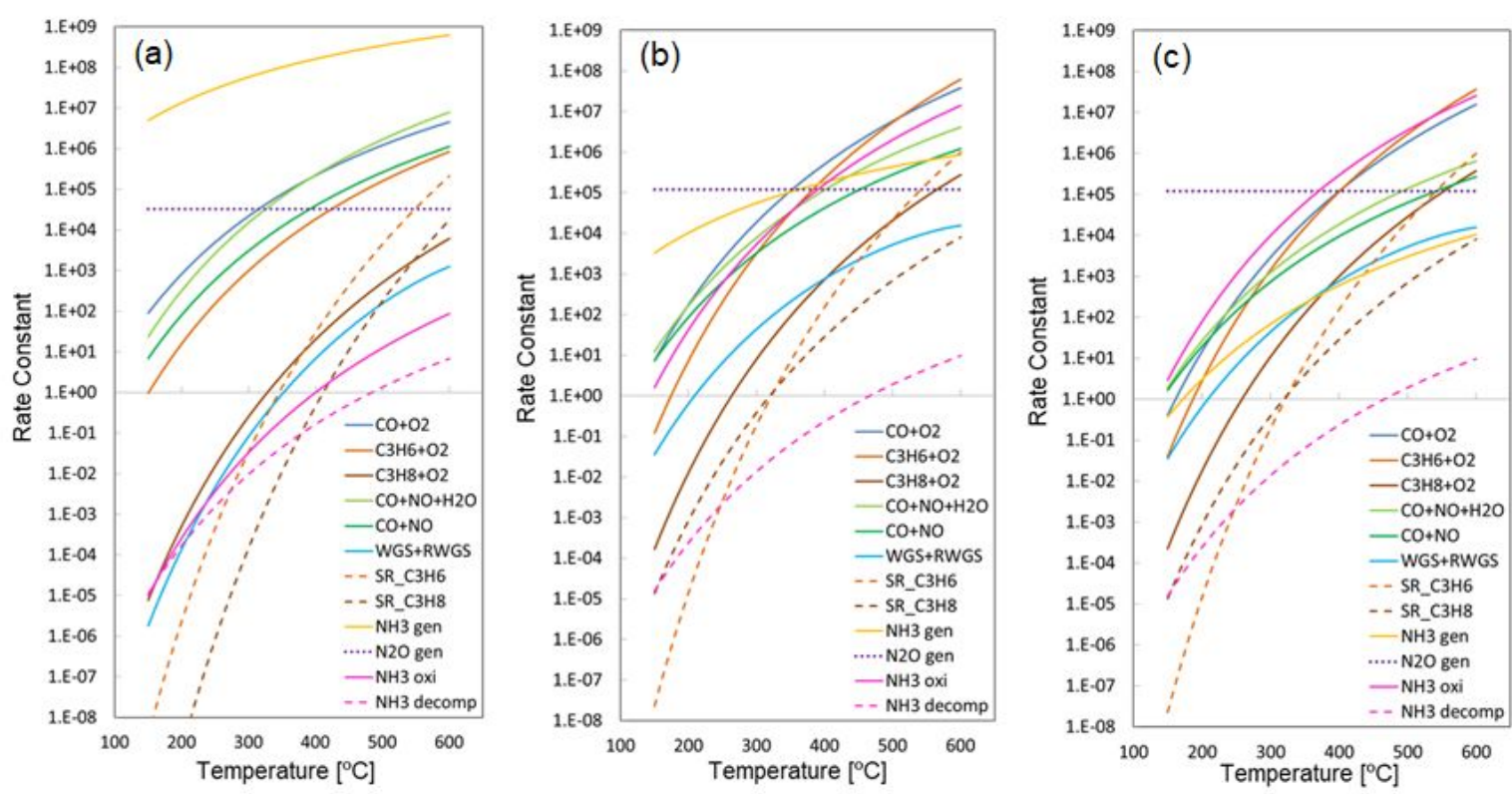

Fig. S16 Comparison of the rate constant as a function of temperature under rich, stoichiometric, and lean conditions: (a) rich; $\lambda=0.91$, (b) stoichiometric; $\lambda=1.00$, and (c) lean; $\lambda=1.03$. [S1]
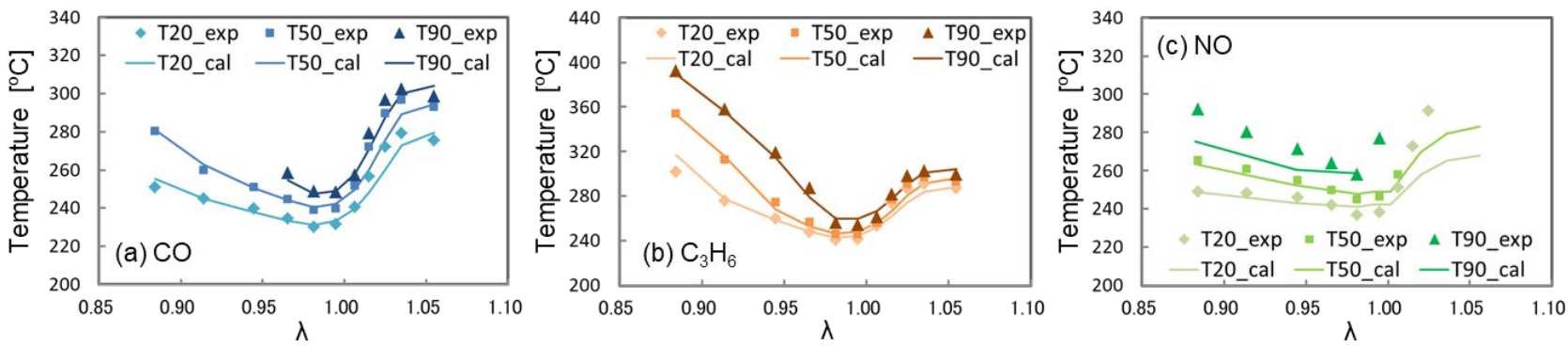

Fig. S17 Comparisons of the experimentally measured and calculated model (previous time of 1-D TWC model) data of $\mathrm{T} 20$, T50, and $\mathrm{T} 90$ for $\mathrm{CO}, \mathrm{C}_{3} \mathrm{H}_{6}$, and $\mathrm{NO}$ conversion rates in the light-off experiment.
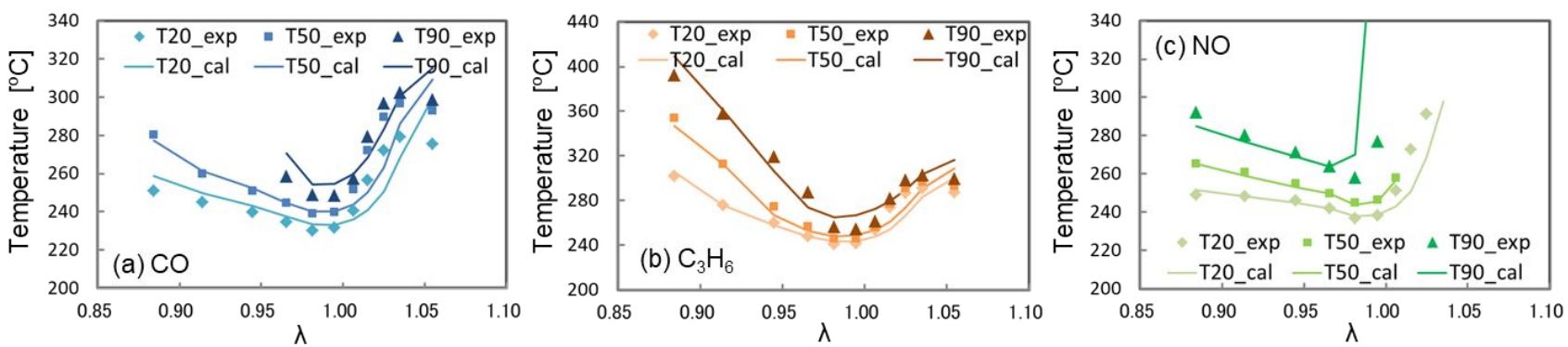

Fig. S18 Comparisons of the experimentally measured and calculated model (Pd/Rh-DL) data of T20, T50, and $\mathrm{T} 90$ for $\mathrm{CO}, \mathrm{C}_{3} \mathrm{H}_{6}$, and $\mathrm{NO}$ conversion rates in the light-off experiment. 


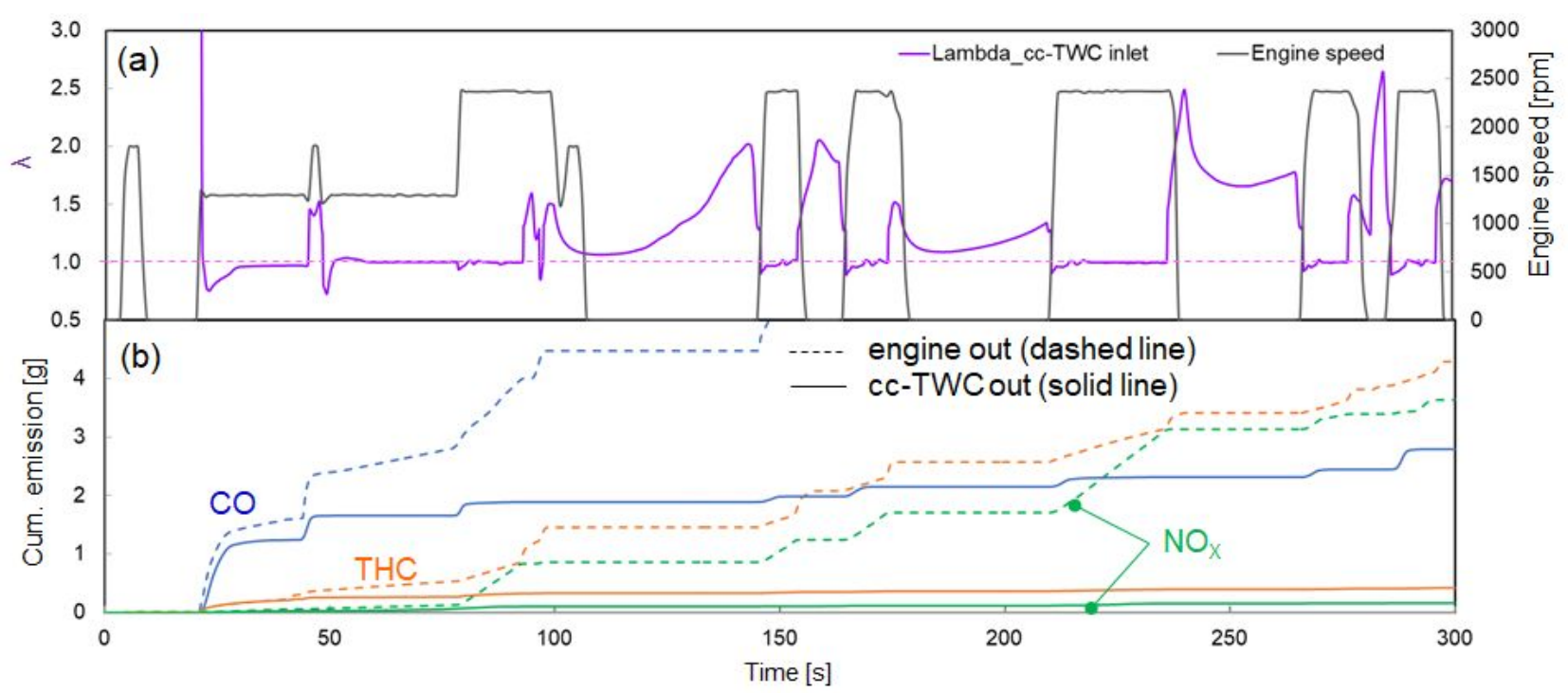

Fig. S19 Vehicle test results at 0-300 s in WLTC mode: (a) $\lambda$ at cc-TWC inlet and engine speed, (b) cumulative emissions of engine out and CC-TWC out for CO, THC and NOx. 
Table S1 Engine specifications [S1].

\begin{tabular}{|c|c|c|}
\hline Engine type & & $\begin{array}{c}\text { Inline } 3 \text { cylinder aluminum with mirror } \\
\text { bore coating }\end{array}$ \\
\hline Displacement & $\mathrm{cc}$ & 1198 \\
\hline Bore $\times$ stroke & $\mathrm{mm}$ & $78.0 \times 83.6$ \\
\hline $\begin{array}{l}\text { Compression } \\
\text { ratio }\end{array}$ & & 12.0:1 \\
\hline Max. power & kW/rpm & $58 / 5400$ \\
\hline Max. torque & $\mathrm{Nm} / \mathrm{rpm}$ & $103 / 3600-5200$ \\
\hline $\begin{array}{l}\text { Various valve } \\
\text { timing control }\end{array}$ & & $\begin{array}{l}\text { Intake: Hydraulic } \\
\text { Exhaust: None }\end{array}$ \\
\hline EGR system & & Cooled EGR \\
\hline Fuel injection & & Multi-point injection \\
\hline
\end{tabular}

Table S2 Vehicle Experimental Conditions [S1].

\begin{tabular}{c|c}
\hline Fuel & Regular gasoline \\
\hline Driving mode & WLTC (except extra high) \\
\hline Ambient Temperature ${ }^{\circ} \mathrm{C}$ & 23 \\
\hline Initial SOC $\%$ & 60 \\
\hline
\end{tabular}

Table S3 Major measured parameters [S1].

\begin{tabular}{|c|c|}
\hline \multirow[t]{3}{*}{ Engine } & Speed [rpm] \\
\hline & Torque $[\mathrm{N} \cdot \mathrm{m}]$ \\
\hline & $\begin{array}{l}\left.\text { Intake pressure }[\mathrm{kPa}] \text {, temperature }{ }^{\circ} \mathrm{C}\right] \\
\text { mass flow }[\mathrm{kg} / \mathrm{h}]\end{array}$ \\
\hline \multirow[t]{5}{*}{ Exhaust } & Gas concentration (cc-TWC In/Out ) [ppm] \\
\hline & $\begin{array}{c}\text { Gas Temperature (cc-TWC In/Out ) }\left[{ }^{\circ} \mathrm{C}\right] \\
\text { TWC Bed Temperature (Front/Mid/Rear) }\left[{ }^{\circ} \mathrm{C}\right]\end{array}$ \\
\hline & Lambda (cc-TWC In/Out) \\
\hline & Pressure (cc-TWC In/Out) [kPa] \\
\hline & Mass Flow $[\mathrm{kg} / \mathrm{h}]$ \\
\hline
\end{tabular}


Table S4 Close-coupled catalyst specifications [S1].

\begin{tabular}{|c|c|c|c|c|}
\hline & & (Original) & $\begin{array}{l}\text { Model gas } \\
\quad \text { exp. }\end{array}$ & Vehicle exp. \\
\hline Diameter & $\mathrm{mm}$ & 99.2 & 25.4 & 103.0 \\
\hline Length & $\mathrm{mm}$ & 90.2 & 50 & 84.0 \\
\hline Volume & cc & 700 & 25.3 & 700 \\
\hline Cell density & cpsi & \multicolumn{2}{|c|}{750} & 600 \\
\hline Channel shape & & \multicolumn{2}{|c|}{ Hexagon } & Hexagon \\
\hline Channel wall thickness & mil & \multicolumn{2}{|c|}{3} & 5 \\
\hline Substrate & & \multicolumn{2}{|c|}{ Cordierite } & Silicon Carbide \\
\hline PGM loading & $g / L$ & \multicolumn{3}{|c|}{$\begin{array}{l}\text { Pd: } 3.429 \\
\text { Rh: } 0.357\end{array}$} \\
\hline Condition & & \multicolumn{3}{|c|}{$\begin{array}{l}\text { Aged on engine bench } \\
\text { (Equivalent to } 10,000 \mathrm{~km} \text { of running time) }\end{array}$} \\
\hline
\end{tabular}

Table S5 Specifications of the model gas test reactor [S1].

\begin{tabular}{cc|c}
\hline \hline Total gas flow rate & $\mathrm{L} / \mathrm{min}$ & $5.0-75.0$ \\
\hline Maximum temperature & ${ }^{\circ} \mathrm{C}$ & (temporal) 800 \\
\hline Temperature ramping rate & ${ }^{\circ} \mathrm{C} / \mathrm{min}$ & $30-50$ \\
\hline Base test piece diameter & $\mathrm{mm}$ & 25.4 \\
\hline
\end{tabular}

Table S6 Comparison of specifications between previous model and new model.

\begin{tabular}{c|c|c|c|c}
\hline \hline & $\begin{array}{c}\text { Previous } \\
\text { model }\end{array}$ & \multicolumn{3}{|c}{ Present models } \\
\hline & Pd + Rh & Pd/Rh-DL & Pd-SL & Rh-SL \\
\hline $\begin{array}{c}\text { Layering } \\
\text { Solution type } \\
\text { (Catalyst layer) }\end{array}$ & 1 -D layer & Double layer & Single layer & Single layer \\
\hline $\begin{array}{c}\text { Washcoat thickness } \\
{[\mu \mathrm{m}]}\end{array}$ & None & $\begin{array}{c}10.9 \text { (Pd layer) } \\
22.2 \text { (Rh layer) }\end{array}$ & 10.9 & 22.2 \\
\hline $\begin{array}{c}\text { Aperture area ratio of } \\
\text { the catalyst } \\
\text { cross-section }\end{array}$ & 0.711 & 0.711 & 0.799 & 0.754 \\
\hline $\begin{array}{c}\text { Gas species diffusion } \\
\text { into catalyst layers }\end{array}$ & $\begin{array}{c}\text { Not available } \\
\text { (Surface } \\
\text { reaction } \\
\text { model) }\end{array}$ & \multicolumn{3}{|c}{ Available } \\
\hline (Random pore model) \\
\hline $\begin{array}{c}\text { Keaction type } \\
\text { Kinetic parameter }\end{array}$ & \multicolumn{4}{|c}{ Global reaction } \\
\hline
\end{tabular}


Table S7 Pore diameters and porosities of the washcoat for the random pore model.

\begin{tabular}{c|c|c|c|c}
\hline & \multicolumn{2}{|c|}{ Macro pore } & \multicolumn{2}{c}{ Micro pore } \\
\hline Pore diameter [nm] & $\mathrm{d}_{\mathrm{a}}$ & 500 & $\mathrm{~d}_{\mathrm{b}}$ & 10 \\
\hline Porosity [-] & $\varepsilon_{\mathrm{a}}$ & 0.20 & $\varepsilon_{\mathrm{b}}$ & 0.35 \\
\hline
\end{tabular}

Table S8 Definitions of input gas compositions for unmeasurable species in WLTC mode simulations [S1].

\begin{tabular}{c|c|c}
\hline \hline \multirow{2}{*}{$\begin{array}{c}\text { Hydrocarbon } \\
\text { species }\end{array}$} & $\mathrm{C}_{3} \mathrm{H}_{6}$ & $45 \%$ of THC measured \\
\cline { 2 - 3 } & $\mathrm{C}_{3} \mathrm{H}_{8}$ & $45 \%$ of THC measured \\
\cline { 2 - 3 } & $\mathrm{CH}_{4}$ & $10 \%$ of THC measured \\
\hline $\mathrm{H}_{2}[\mathrm{~S} 2]$ & {$\left[\mathrm{H}_{2}\right]=\frac{\mathrm{n}}{2} \frac{[\mathrm{CO}]\left([\mathrm{CO}]+\left[\mathrm{CO}_{2}\right]\right)}{[\mathrm{CO}]+\left[\mathrm{CO}_{2}\right] / K_{w}}$} \\
& $\mathrm{~K}_{w}=0.285, n=1.85$ \\
\hline
\end{tabular}

The ratio of $\mathrm{HC}$ among $\mathrm{C}_{3} \mathrm{H}_{6}, \mathrm{C}_{3} \mathrm{H}_{8}$ and $\mathrm{CH}_{4}$ is quite difficult to detect on a general chassis-dynamo test bench. This time we assumed that ratio to be $0.45: 0.45: 0.10$, respectively [S3]. 


\section{Kinetic parameter control-1 [S1]}

In our previous study, it was verified that the kinetic parameters for each reaction can vary with $\lambda$. However, the $\lambda$ range and width, that is, the $\lambda$ range within which $A$ and $E_{a}$ change and the width of the $\lambda$ range, differ for each reaction. Consequently, to implement kinetic parameter control (KPC) along with $\lambda$ into this TWC model, a term to define the effective $\lambda$ range was adopted [Eq. (S1)]. Moreover, for reaction $j$, when multiplying $f_{j}(\lambda)$, the value of which is variable between 0 and 1 based on the specified threshold of $\lambda\left(\lambda_{0, j}\right)$, by the rate constant the reaction can only become effective at the rich or lean side. Notably, the $\lambda$ width range, where $f_{j}$ $(\lambda)$ varies from 0 to 1 , is fixed at approximately 0.054 of the $\lambda$ width. This inconvenience may impose a severe effect on the reproduction of the kinetic parameter changes. However, when this width is narrowed, there are risks for aborts under calculation in transient mode simulation by errors and heavier calculation costs by the increased instability. At this junction, the rate constant equation is described by Eq. (S2.1) for the rich dominant reactions and Eq. (S2.2) for the lean dominant reactions. Two individual rate constant equations were set for one reaction - $k_{\text {base,j }}$ [Eq. (S3.1)], which is all effective regardless of $\lambda$, and $k_{\text {rich, }}$ [Eq. (S3.2)] or $k_{\text {lean,j }}$ [Eq. (S3.3)], which are only effective on the rich and lean sides, respectively - followed by the separate application of each kinetic parameter. Thus, the reaction rate equation is determined by Eq. (S4). This KPC is described as $\mathrm{KPC}-1$

$$
\begin{gathered}
f_{j}(\lambda)=\frac{1}{\exp \left\{105\left(\lambda_{0, j}-\lambda\right)\right\}+1} \\
k_{k p c 1, j}=k_{\text {base } 1, j}+\left(1-f_{j}(\lambda)\right) \cdot k_{\text {rich } 1, j}(\text { Rich dominant reaction) } \\
k_{k p c 1, j}=k_{\text {base } 1, j}+f_{j}(\lambda) \cdot k_{\text {lean } 1, j} \text { (Lean dominant reaction) } \\
k_{\text {base } 1, j}=A_{\text {base } 1, j} \cdot \exp \left(-E_{\text {base } 1, j} / R T\right) \\
k_{\text {rich } 1, j}=A_{\text {rich } 1, j} \cdot \exp \left(-E_{\text {rich } 1, j} / R T\right) \\
k_{\text {lean } 1, j}=A_{\text {lean } 1, j} \cdot \exp \left(-E_{\text {lean } 1, j} / R T\right) \\
r_{k p c 1, j}=\frac{k_{k p c 1, j}[\mathrm{a}]^{\alpha 1_{j}}[\mathrm{~b}]^{\alpha 2_{j}} T^{\beta_{j}}}{G \cdot G_{m}^{\prime}}
\end{gathered}
$$

\section{Kinetic parameter control-2 [S1]}

When the rate constant takes a maximum value around the stoichiometric side, however, it is impossible to reflect the trend of the rate constant fluctuation by means of the above method. To address this complex issue, three reaction equations for rich, stoichiometric, and lean conditions, respectively, and their rate constants $\left(k_{\text {rich } 2, j}, k_{\text {stoi } 2, j}, k_{\text {lean } 2, j}\right.$, respectively) with kinetic parameters for each one were prepared, and the occupancies 
for each active site $\left(\theta_{P G M_{-} R, j}, \theta_{P G M_{-} S, j,}, \theta_{P G M_{L} L, j}\right.$, respectively)) were controlled to be assigned along with the instantaneous $\lambda$ [Eqs. (S5.1)-(S5.3)]. In particular, by introducing the effective $\lambda$ range setting terms $f_{R, j}(\lambda)$ and $f_{L, j}(\lambda)$ similarly to the above [Eqs. (S6.1)-(S6.2)], another control method for varying the occupation rates for the three reaction sites was adopted. This KPC is described as KPC-2, which is distinct from KPC-1. The total reaction rate $r_{k p c 2, j}$ and rate constant $k_{k p c 2, j}$ are described by Eq. (S7) and Eq. (S8), respectively, using the sum of three products of the reaction rate and reaction site occupancy for each $\lambda$ condition. For the rich and lean sides, respectively, $\lambda_{0 R, j}$ and $\lambda_{0 L, j}$ are the $\lambda$ threshold values and the sum of each reaction site occupancy is 1 [Eq. (S9)]. Assigning the changing rates of the active site occupancies between $\theta_{P G M_{-} R, j}$ and $\theta_{P G M_{-} S, j}$ along with $\lambda$ as $r_{R \rightarrow S, j}$ (from $\theta_{P G M_{-} R, j}$ to $\theta_{P G M_{-} S, j}$ ) and $r_{S \rightarrow R, j}$ (from $\theta_{P G M_{-} S, j}$ to $\theta_{P G M_{-} R, j}$ ) and similarly those between $\theta_{P G M_{-} S, j}$ and $\theta_{P G M_{-} L, j}$ as $r_{S \rightarrow L, j}$ (from $\theta_{P G M_{-} S, j}$ to $\theta_{P G M_{-} L, j}$ ) and $r_{L \rightarrow S, j}$ (from $\theta_{P G M_{-} L, j}$ to $\theta_{P G M_{-} S, j}$ ), the four are described as functions solely depending on $\lambda$ by Eqs. (S10.1)-(S10.4). Each one is the product of the rate constant consisting of the effective $\lambda$ range setting term $f_{R, j}(\lambda)$ or $f_{L, j}(\lambda)$ and the former active site occupancy.

$$
\begin{aligned}
& k_{\text {rich } 2, j}=A_{\text {rich } 2, j} \cdot \exp \left(-E_{\text {rich } 2, j / R T}\right) \\
& k_{\text {stoi2 }, j}=A_{\text {stoi2, }, j} \cdot \exp \left(-E_{\text {stoi }, j} / R T\right) \\
& k_{\text {lean } 2, j}=A_{\text {lean } 2, j} \cdot \exp \left(-E_{\text {lean } 2, j} / R T\right) \\
& f_{R, j}(\lambda)=\frac{1}{\exp \left\{105\left(\lambda-\lambda_{0 R, j}\right)\right\}+1} \\
& f_{L, j}(\lambda)=\frac{1}{\exp \left\{105\left(\lambda_{0 L, j}-\lambda\right)\right\}+1} \\
& r_{k p c 2, j}=\frac{k_{k p c 2, j}[\mathrm{a}]^{\alpha 1_{j}}[\mathrm{~b}]^{\alpha 2_{j}} T^{\beta_{j}}}{G \cdot G_{m}^{\prime}} \\
& k_{k p c 2, j}=k_{\text {rich } 2, j} \cdot \theta_{P G M_{-} R, j}+k_{\text {stoi } 2, j} \cdot \theta_{P G M_{-}, j}+k_{\text {lean } 2, j} \cdot \theta_{P G M_{-} L, j} \\
& \theta_{P G M_{-} R, j}+\theta_{P G M_{-} S, j}+\theta_{P G M_{-} L, j}=1 \\
& r_{R \rightarrow S, j}=1 \cdot\left(1-f_{R, j}(\lambda)\right) \cdot \theta_{P G M_{-} R, j} \\
& r_{S \rightarrow R, j}=1 \cdot f_{R, j}(\lambda) \cdot \theta_{P G M_{-} S, j} \\
& r_{S \rightarrow L, j}=1 \cdot f_{L, j}(\lambda) \cdot \theta_{P G M_{-} S, j} \\
& r_{L \rightarrow S, j}=1 \cdot\left(1-f_{L, j}(\lambda)\right) \cdot \theta_{P G M_{L} L, j}
\end{aligned}
$$


Considering $r_{R \rightarrow S, j}=r_{S \rightarrow R, j}$ and $r_{R \rightarrow S, j}=r_{S \rightarrow R, j}$ when $\lambda$ stabilizes in a steady value

$$
\begin{aligned}
\theta_{P G M_{-} R, j} & =\frac{f_{R, j}(\lambda)}{1-f_{R, j}(\lambda)} \theta_{P G M_{-} S, j} \\
\theta_{P G M_{-} L, j} & =\frac{f_{L, j}(\lambda)}{1-f_{L, j}(\lambda)} \theta_{P G M_{-} S, j}
\end{aligned}
$$

Thus, $\theta_{P G M_{-} S, j}$ can be determined by $\lambda$ according to Eq. (S12), and $\theta_{P G M_{-} R, j}$ and $\theta_{P G M_{-} L, j}$ are also fixed.

$$
\left(\frac{f_{R, j}(\lambda)}{1-f_{R, j}(\lambda)}+1+\frac{f_{L, j}(\lambda)}{1-f_{L, j}(\lambda)}\right) \theta_{P G M_{-}, j}=1
$$

\section{Notations}

$R$ : Gas constant [J/K.mol]

$G$ : Inhibition factor

$G_{m}^{\prime}$ : Additional inhibition multiplier

For reaction $j$ in the case adopting KPC-1:

$k_{k p c 1, j}:$ Rate constant

$r_{k p c 1, j:}$ Reaction rate [mol/mol-site.s]

$k_{\text {base } 1, j}, k_{\text {rich } 1, j}, k_{\text {lean } 1, j}:$ Rate constants for base, rich, and lean active sites, respectively

$A_{\text {base } 1, j}, A_{\text {rich } 1, j}, A_{\text {lean } 1, j}$ : Frequency factors for base, rich, and lean active sites, respectively

$E_{\text {base } 1, j}, E_{\text {rich1,j, }}, E_{\text {lean } 1, j}$ : Activation energies for base, rich, and lean active sites, respectively, [kJ/mol]

For reaction $j$ in the case adopting KPC-2

$k_{k p c 2, j}:$ Rate constant

$r_{k p c 2, j:}$ Reaction rate $[\mathrm{mol} / \mathrm{mol}-\mathrm{site} . \mathrm{s}]$ 
$k_{\text {rich } 2, j}, k_{s t o i 2, j}, k_{\text {lean } 2, j}:$ Rate constants for rich, stoichiometric, and rich active sites, respectively

$A_{\text {rich } 2, j}, A_{\text {stoiz } 2, j}, A_{\text {lean } 2, j}$ : Frequency factors for rich, stoichiometric, and lean active sites, respectively

$E_{\text {rich } 2, j}, E_{\text {stoi2,j, }}, E_{\text {lean } 2, j}:$ Activation energies for rich, stoichiometric, and lean active sites, respectively, [kJ/mol]

$r_{R \rightarrow S, j}$ : Changing rate of active site occupancies from rich to stoichiometric

$r_{S \rightarrow R, j}:$ Changing rate of active site occupancies from stoichiometric to rich

$r_{S \rightarrow L, j}:$ Changing rate of active site occupancies from stoichiometric to lean

$r_{L \rightarrow S, j}$ : Changing rate of active site occupancies from lean to stoichiometric

\section{Greek Symbols}

$\lambda$ : Air excess ratio

$\lambda_{0, j}:$ Threshold value of lambda for reaction $j$ in the case adopting KPC-1

$\lambda_{0 R, j}, \quad \lambda_{0 L, j}$ : Threshold values of lambda for rich and lean sides, respectively for reaction $j$ in the case adopting KPC-2

$\theta_{P G M_{-} R, j}, \theta_{P G M_{-} S, j}, \theta_{P G M_{-} L, j}:$ Occupancies for rich, stoichiometric, and lean active sites, respectively for reaction $j$ in the case adopting KPC-2

\section{References}

[S1] Okajima, T.; Sivakumar, S.; Shingyouchi, H.; Yamaguchi, K.; Kusaka, J.; Nagata, M. Modeling on a three-way catalyst used in series hybrid electric vehicles considering its specific engine operation attribute, Ind. Eng. Chem. Res. 2021, 60, 1583-1601.

[S2] Ramanathan, K.; Sharma, C.S. Kinetic Parameters Estimation for Three Way Catalyst Modeling, Ind. Eng. Chem. Res. 2011, 50, 9960-9979.

[S3] Kubo, S. Formation and Emission Characteristics of Unburned Hydrocarbons during Cold Start of a Spark-Ignited Engine System. Research Report. Technical Journal / R\&D Review of Toyota CRDL, 1995, 30, No. 2 (1995.6). 